\title{
Determination of selected hormones
} and biochemical parameters

\section{in Turkish Van cats with tail gland hyperplasia")}

\author{
CUMALİ OZKAN, ABDULLAH KAYAR*, ABDULLAH KAYA, SERKAN YILLDIRIM**, \\ ONUR ISKEFLIं*, SULEYMAN KOZAT, YAKUP AKGUL
}

\begin{abstract}
Van Yuzuncu Yil University, Faculty of Veterinary Medicine, Department of Internal Medicine, Van, Turkey
*Istanbul University-Cerrahpasa, Faculty of Veterinary Medicine, Department of Internal Medicine, İstanbul, Turkey

${ }^{* *}$ Ataturk University, Faculty of Veterinary Medicine, Department of Pathology, Erzurum, Turkey
\end{abstract}

\section{Ozkan C., Kayar A., Kaya A., Yildirim S., Iskefli O., Kozat S., Akgul Y. Determination of selected hormones and biochemical parameters in Turkish Van cats with tail gland hyperplasia}

\section{Summary}

The present study was performed on Turkish Van cats with tail gland hyperplasia in order to determine changes in some hormone levels and biochemical parameters. Animal material consisted of 18 male Van cats of between 2-8 years of age, 12 with tail gland hyperplasia and 6 unaffected cats as the control group. Following routine clinical examination, hormone levels and biochemical parameters were measured by obtaining blood samples, and biopsy samples were obtained from the region and examined under a light microscope. When compared with the control group, testosterone levels were high although the difference between groups was not statistically significant. Similarly, no statistical significance was found between the groups in terms of other hormones. Among the hormonal parameters, the only remarkable increase was seen in the testosterone level. Among biochemical parameters, the alkaline phosphatase (ALP), aspartate amino transferase (AST), cholesterol and triglyceride levels were statistically different, while other biochemical parameters were not statistically significant. While AST and cholesterol results were increased, ALP and triglyceride levels were decreased. As a result, we conclude that the disease is an important problem which occurs extensively in mature male Van cats, particularly during and after mating periods. We also conclude that the disease might be associated with an increase in testosterone levels. Presenting this study is beneficial as there are limited reports about this disease in cats. This is the first study presenting tail gland hyperplasia with some hormonal levels and biochemical parameters in male Van cats.

Keywords: biochemical parameters, hormonal levels, tail gland hyperplasia, stud tail, Van cat

The Turkish Van cat is a well-known species, known for white silk fur, different eye colors, friendly behavior, and a fondness for water. In recent years, Van cats have been the subject of several scientific studies (11, $13,20)$. In these studies, numerous physiological characteristics, disorders, genetic structures, and changes in hematological and biochemical parameters were investigated, although none of the studies to date have investigated the hormonal and biochemical parameters associated with tail gland hyperplasia in Van cats.

The tail - or supracaudal - gland is an organ rich with lipid and apocrine glands, located in the dorsal region

1) The authors thank the Van Yuzuncu Yil University, Scientific Research Projects for their support in this study. This study was supported by Van Yuzuncu Yi University, Scientific Research Projects Board with project no: THD-2017-5940. of the tail in carnivores, surrounded by erector muscles of the hair $(14,15,17)$. It has a glandular structure and secretes lipoprotein on the skin surface (3). This gland is associated with hair follicles and secrets sebum, a sebaceous liquid, on the skin surface through numerous sebaceous glands $(1,16,17)$. These sebaceous glands maintain skin health and hair moisture. When hyperplasia of the gland occurs, excessive sebaceous liquid is secreted and this leads to an accumulation on the surface of the skin. This condition is termed "stud tail" or "tail gland hyperplasia" $(2,3,19)$.

Tail gland hyperplasia results from the causes of primary and secondary seborrhea, increases in androgen hormone levels, hypothyroidism, and testicular tumors $(6,14,18)$. In the disease, hyperplasia induces 
the secretion of excessive seborrheic content and this leads to dirtiness of the area and skin lesions on the tail. Additionally, libido and aggressive behavior increases in male cats, and female animals tend toward masculine behaviors $(2,12,15)$. The disease may be suspected from clinical symptoms, but definitive diagnosis is made by histopathological examinations, measuring serum testosterone levels and culture examinations are necessary when secondary infections accompany the disease $(6,15,18)$. It is reported that androgen hormones lead to hyperplasia of seborrheic glands and, as a result, increased secretion occurs (15, 18). However, occurrence of tail gland hyperplasia in castrated animals means that the relationship between hormonal balance and the disease is unresolved. It is also stated that the effect of androgen hormones on this condition is not completely clear (15).

The purpose of our study was to determine hormonal and biochemical parameters in male Turkish Van cats with tail gland hyperplasia, as well as to investigate these parameters in relation to this disease.

\section{Material and methods}

The material of this study consisted of 18 male Turkish Van cats of between 2 and 8 years of age, 12 with tail gland hyperplasia and 6 healthy cats as the control group. All cats reside at the Van Yuzuncu Yil University Van Cat Research and Practice Center. This study was approved by Van Yuzuncu Yil University (Turkey) Animal Researches Local Ethic Committee with protocol number, 2017/02.

Routine clinical examination of the animals was performed and macroscopical findings were photographed. Blood samples were taken from vena radialis (v. cephalica) in anticoagulant free tubes in order to analyse hormonal and biochemical parameters. The blood samples were centrifuged at 3000 RPM (Rotofix $32^{\circledR}$-Hettich) and serum samples were extracted and stored at $-20^{\circ} \mathrm{C}$ until the analyses.

Testosterone, insulin, progesterone, thyroid-stimulating hormone (TSH), triiodothyronine $\left(\mathrm{T}_{3}\right)$, free triiodothyronine $\left(\mathrm{fT}_{3}\right)$ and free thyroxine ( $\left.\mathrm{fT}_{4}\right)$ levels were analyzed using an IMMULITE 2000 hormone device. Serum total protein (TP), albumin, globulin, glucose, blood urea nitrogen (BUN), creatinine, aspartate amino transferase (AST), alkaline phosphatase (ALP), alanine aminotransferase (ALT), lactate dehydrogenase $(\mathrm{LDH})$, creatine kinase $(\mathrm{CK})$ and creatine kinase-MB (CK-MB), amylase, total bilirubin, calcium $(\mathrm{Ca})$, magnesium $(\mathrm{Mg})$, phosphorus $(\mathrm{P})$, cholesterol, triglyceride, sodium $(\mathrm{Na})$, potassium $(\mathrm{K})$, and chloride $(\mathrm{Cl})$ levels were analyzed using an auto-analyzer device (RocheHitachi Cobas-6000 c501).

In order to perform histopathological examinations, tissue samples were obtained from 3 cats; 2 with tail gland hyperplasia and 1 from the control group. The region was shaved and disinfected. Biopsy samples were obtained from the dorsal region of the tail under local anesthetic and the site was closed with a single suture. These samples were fixed in $10 \%$ formalin solution for 48 hours and washed under flowing tap water for 10 hours. For routine tissue tracing, the samples were passed through alcohol $\left(70^{\circ}, 80^{\circ}, 90^{\circ}, 96^{\circ}\right.$,

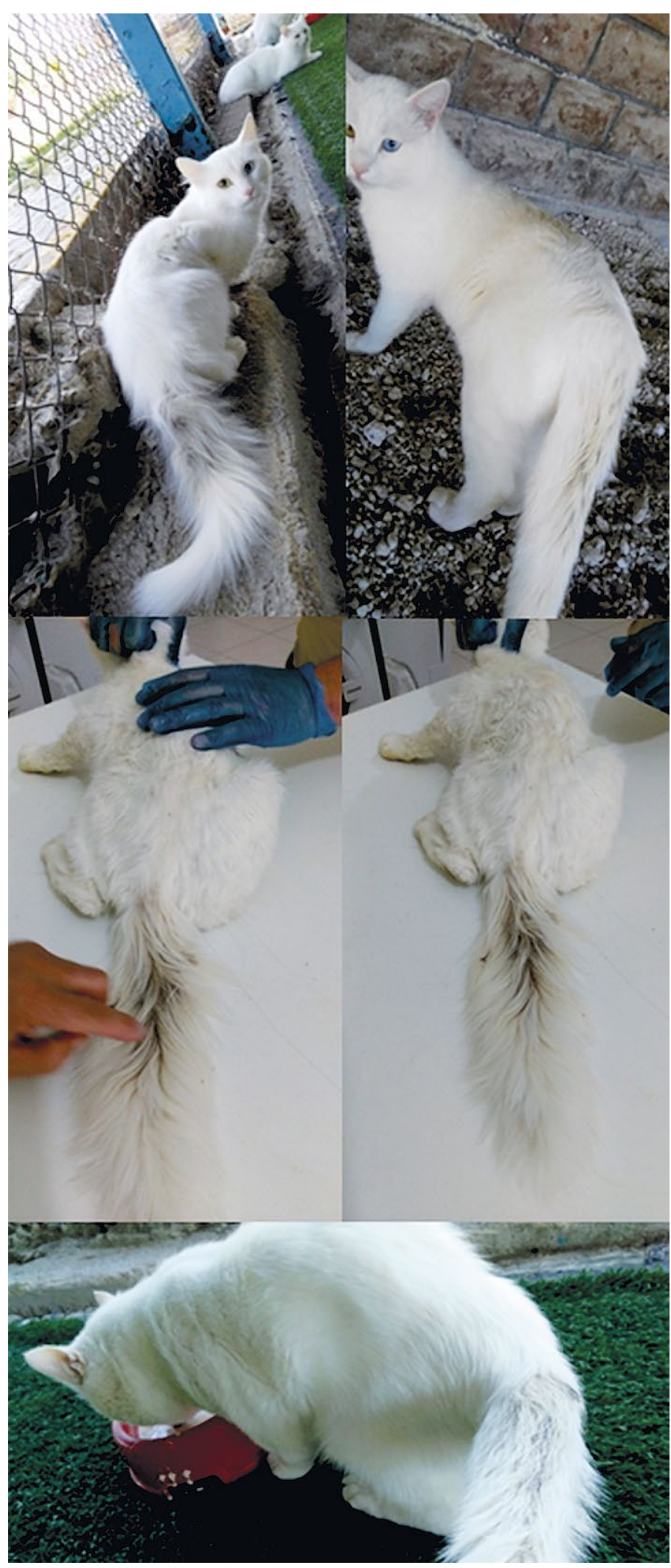

Fig. 1. Tail gland hyperplasia in Van cats (dirty and seborrheic appearance of the area due to the excessive secretion of seborrheic content on the tail)

$100^{\circ}$ ) and xylol series and embedded in paraffin blocks. Sections of $4 \mu \mathrm{m}$ thickness were obtained from each block and the preparations were stained with hematoxylin and eosin (H\&E) and examined under a light microscope.

Statistical evaluation of the data was performed using SPSS 20.0 software. Mean and SEM values were determined 
in both control and study groups. The independent sample t-test was applied for the statistical comparison of these values, and $\mathrm{p}<0.05$ values were accepted as significant.

\section{Results and discussion}

Clinical findings. During the clinical examinations of the study group, clinical findings were only observed in the dorsal part of the tail. As a result of tail gland hyperplasia, the area and regional hair were seborrheic, and crustations were visible on the skin surface. Local alopecia, thinning of and loss of gloss in the hair, as well hyperpigmentation were observed, caused by excessive seborrheic content covering the skin. Due to the animals' white fur, the dark, dirty patches drew attention as a result of dust sticking to the seborrheic area (Fig. 1). Additionally, increases in libido and aggressive behavior were observed in the cats with tail gland hyperplasia.

Biochemical findings. Mean values, standard errors, and statistical comparisons of hormone levels in the study and control groups are given in Table 1. Analysis revealed no statistically significant differences between the groups. Testosterone levels were not particularly significant, although higher in the study group (452.42 $\pm 68.84 \mathrm{ng} / \mathrm{dL})$ than in the control group $(315.83$ $\pm 76.39 \mathrm{ng} / \mathrm{dL}$ ).

Mean values, standard errors, and statistical comparisons of biochemical parameters for both groups are given in Table 2. Analysis revealed statistical differences in biochemical parameters, such as levels of $\operatorname{ALP}(\mathrm{p}<0.01), \operatorname{AST}(\mathrm{p}<0.05)$, cholesterol $(\mathrm{p}<0.05)$ and triglyceride $(\mathrm{p}<0.05)$. Other biochemical parameters presented no statistically significant differences between the groups.

Histopathological findings. Macroscopical examination of the dorsal region of the tail in cats with tail gland hyperplasia found that the hair was untidy, seborrheic, and glued together. The area had a dirty, tacky, black-brown appearance. After shaving the hair, the region was observed to be edematous and swollen.

Microscopically, muscular hyperplasia on the supracaudal glands and muscle trabeculae around the hair follicles were observed in the histopathological preparations in cats with tail gland hyperplasia. In these cases, several glands developed as lobules which proceeded towards the dermis. At the middle of these lobules, adult sebocytes and increased secretions led to dilated glands (Fig. 2). Microscopically, normal histological structure of the tail skin, epidermis and dermis layers were observed in the histopathological preparation of the healthy cat.

This study was performed in order to determine changes in hormone levels and biochemical parameters in male Turkish Van cats, and to present the relevance of these parameters to tail gland hyperplasia.

The routine clinical examinations of the study group revealed no clinical findings other than in the dorsal part of the tail. Due to hyperplasia, seborrheic hair,
Tab. 1. Some hormone levels in control and study groups $(\overline{\mathbf{x}} \pm$ SEM)

\begin{tabular}{|l|c|c|c|}
\hline \multicolumn{1}{|c|}{ Parameters } & $\begin{array}{c}\text { Control group } \\
(\mathrm{n}=6)\end{array}$ & $\begin{array}{c}\text { Study Group } \\
(\mathrm{n}=12)\end{array}$ & $p$ \\
\hline Testosterone $(\mathrm{ng} / \mathrm{dL})$ & $315.83 \pm 76.39$ & $452.42 \pm 68.84$ & NS \\
Insulin $(\mu \mathrm{U} / \mathrm{mL})$ & $1.18 \pm 0.78$ & $0.69 \pm 0.09$ & NS \\
Progesteron $(\mathrm{ng} / \mathrm{ml})$ & $0.07 \pm 0.03$ & $0.24 \pm 0.17$ & NS \\
$\mathrm{TSH}(\mathrm{ng} / \mathrm{ml})$ & $0.17 \pm 0.05$ & $0.21 \pm 0.04$ & NS \\
$\mathrm{T}_{3}(\mathrm{ng} / \mathrm{dL})$ & $30.00 \pm 5.08$ & $29.83 \pm 3.43$ & NS \\
$\mathrm{fT}_{3}(\mathrm{pmol} / \mathrm{L})$ & $2.95 \pm 0.31$ & $2.56 \pm 0.13$ & NS \\
$\mathrm{fT}_{4}(\mathrm{ng} / \mathrm{dL})$ & $1.35 \pm 0.17$ & $1.39 \pm 0.17$ & NS \\
\hline
\end{tabular}

Explanation: $\mathrm{NS}-\mathrm{p}>0.05$

Tab. 2. Some biochemical parameters in control and study groups $(\overline{\mathbf{x}} \pm \mathrm{SEM})$

\begin{tabular}{|l|c|c|c|}
\hline \multicolumn{1}{|c|}{ Parameters } & $\begin{array}{c}\text { Control group } \\
(\mathrm{n}=6)\end{array}$ & $\begin{array}{c}\text { Study group } \\
(\mathrm{n}=12)\end{array}$ & $\mathrm{p}$ \\
\hline Total protein (g/dL) & $7.50 \pm 0.16$ & $8.09 \pm 0.36$ & NS \\
\hline Albumin (g/dL) & $3.50 \pm 0.15$ & $3.34 \pm 0.11$ & NS \\
\hline Globulin (g/dL) & $4.17 \pm 0.31$ & $5.17 \pm 0.47$ & NS \\
\hline Glucose (mg/dL) & $63.17 \pm 5.54$ & $54.38 \pm 4.14$ & NS \\
\hline BUN (mg/dL) & $18.83 \pm 0.70$ & $20.08 \pm 0.66$ & NS \\
Creatinine (mg/dL) & $1.16 \pm 0.05$ & $1.20 \pm 0.05$ & NS \\
\hline AST (U/L) & $17.12 \pm 1.33$ & $41.07 \pm 7.86$ & $*$ \\
ALP (U/L) & $41.17 \pm 7.26$ & $23.67 \pm 2.03$ & $*$ \\
\hline ALT (U/L) & $33.42 \pm 3.88$ & $82.53 \pm 19.57$ & NS \\
LDH (U/L) & $120.33 \pm 24.96$ & $162.08 \pm 18.40$ & NS \\
CK (U/L) & $119.50 \pm 18.08$ & $223.17 \pm 57.61$ & NS \\
CK-MB (U/L) & $37.62 \pm 22.98$ & $48.07 \pm 16.22$ & NS \\
\hline Amylase (U/L) & $1278.50 \pm 241.58$ & $1255.30 \pm 91.11$ & NS \\
\hline Total bilirubin (mg/dL) & $0.02 \pm 0.00$ & $0.03 \pm 0.00$ & NS \\
\hline Ca (mg/dL) & $8.99 \pm 0.28$ & $9.31 \pm 0.16$ & NS \\
\hline Mg (mg/dL) & $2.06 \pm 0.05$ & $2.10 \pm 0.06$ & NS \\
\hline P (mg/dL) & $5.26 \pm 0.36$ & $5.08 \pm 0.15$ & NS \\
Cholesterol (mg/dL) & $110.43 \pm 9.66$ & $142.41 \pm 8.56$ & $*$ \\
\hline Triglyceride (mg/dl) & $54.17 \pm 9.95$ & $34.84 \pm 3.45$ & $*$ \\
\hline Na (mmol/L) & $152.00 \pm 1.03$ & $152.33 \pm 1.53$ & NS \\
\hline K (mmol/L) & $4.58 \pm 0.09$ & $4.80 \pm 0.15$ & NS \\
Cl (mmol/L) & $110.85 \pm 0.73$ & $112.37 \pm 1.17$ & NS \\
\hline F & & & \\
\hline
\end{tabular}

Explanations: NS $-\mathrm{p}>0.05,{ }^{*}-\mathrm{p}<0.05, * *-\mathrm{p}<0.01$

crustations on the skin surface, thinning of the surrounding hair, alopecia, loss of gloss, hair fractures, and hyperpigmentation were observed. Excessive secreted content on the skin led to seborrhea and dirt in the regional hair. As the cats had white hair, the black, dirty and seborrheic appearance of the region drew attention (Fig. 1). Moreover, observations were made that cats with tail gland hyperplasia displayed increased libido and aggressive behavior. These mentioned clinical findings were similar to those reported in previous studies $(12,15,18,19)$. 

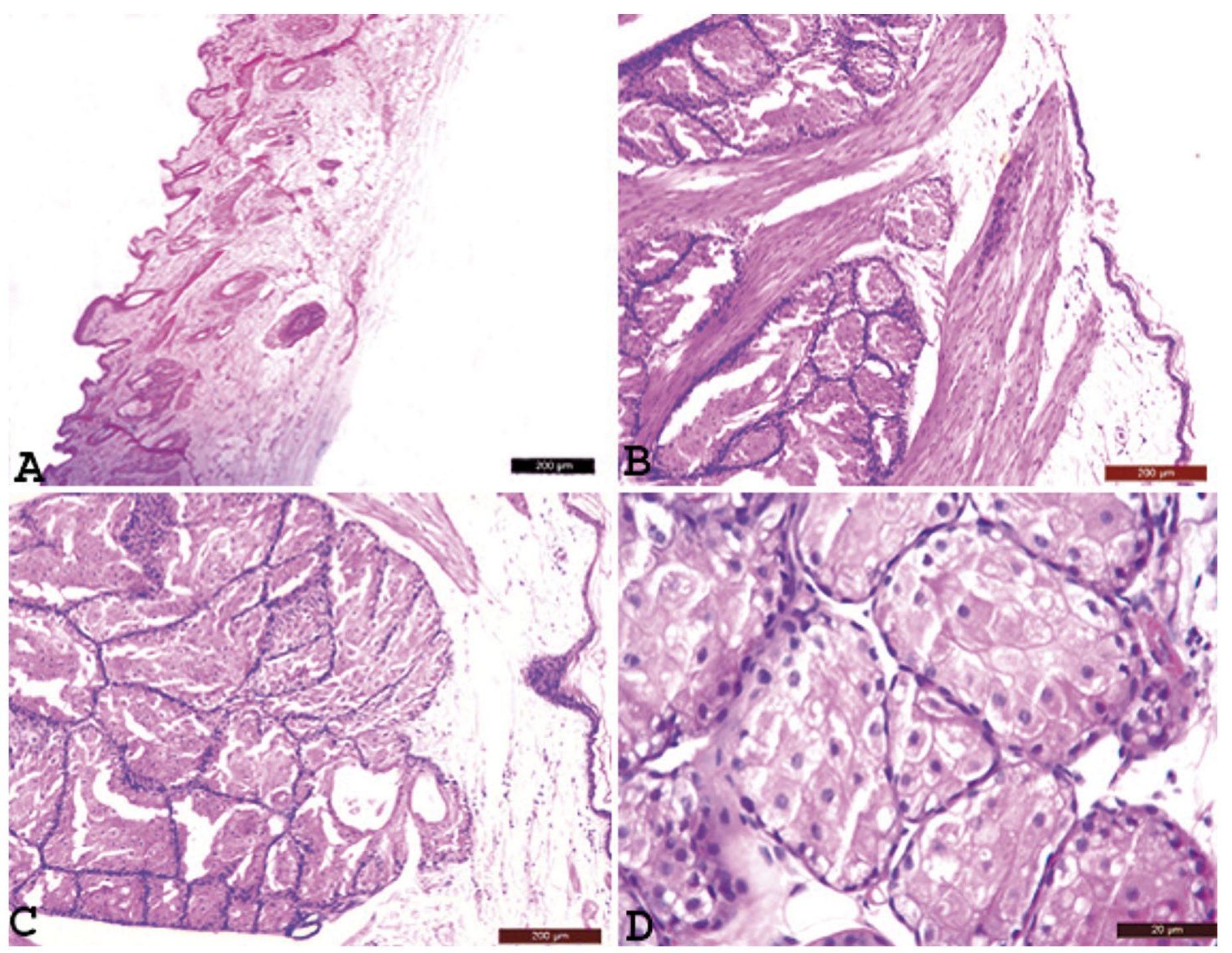

Fig. 2. A. Normal histological structure of the tail gland in a healthy cat (H\&E Bar: $200 \mu \mathrm{m})$. B. Muscular hyperplasia in the muscle trabecules around hair follicles (H\&E Bar: $200 \mu \mathrm{m})$. C. Hyperplasia in seborrheic glands (H\&E Bar: $200 \mu \mathrm{m})$. D. Adult seborrheic cells in the middle of seborrheic glands (H\&E Bar: $200 \mu \mathrm{m}$ )

It is reported that clinical symptoms may lead to suspicion of the disease but that certain diagnosis is made histopathologically $(1,14,15)$. According to our histopathological examinations, hyperplasia was observed in the glandular area. In this study, and in keeping with the above reports, dorsal hair was untidy, seborrheic, and stuck together. We also observed that the area was dark brown, dirty, and sticky. When the hair was shaved, an edematous and swollen appearance was observed. Microscopically, muscular hyperplasia had formed on the sebaceous glands around the hair follicles and muscle trabeculae had formed on the skin. In these glands, several glands developed as lobules and processed deeply to the dermis. Dilated glands were also observed in the middle of these lobules, induced by adult sebocytes and secretions (Fig. 2). According to our findings, tail gland hyperplasia was therefore detected in these animals.

It is reported that androgen hormones have an effect on hair follicles and sebaceous glands on the skin, and can lead to seborrheic gland formations along with an increase in secretions $(4,12)$. Previous studies performed on humans reported that androgens are responsible for the formation of acne. After treatment, a decrease in androgen hormone levels was determined which paralleled recovery, and attention to hormonal disorders in relation to this disease was emphasized $(5,10)$.

According to previous reports, tail gland hyperplasia occurred severely in male cats, and it progressed mildly in females and castrated male animals $(15,16)$. In several other studies it is reported that an increase in androgenic hormone levels might have a role in tail gland hyperplasia $(4,5,10,12)$. In contrast, occasional occurrence of the disease in castrated male and female animals means that the relation of tail gland hyperplasia with hormonal balance is unresolved (15).

The role of breed predisposition in the formation of the disease is not clearly known, although it is reported that the disease is commonly seen in adult cats and $\operatorname{dogs}(16,18)$. In the present study, the disease was also seen in adult male cats more than 2 years of age. It is 
therefore determined that the disease is an important problem in male animals which progresses severely during and after mating seasons.

As a result of these observations, it was determined that the disease is seen in female animals more rarely than in male cats in the same environment. For this reason, we performed the current study with male Turkish Van cats to observe the disease particularly in males, during and after mating season. Thus, and parallel with several previous studies $(4,5,10)$, we conclude that an increase in androgen hormone levels may play a part in Van cat tail gland hyperplasia, and that evaluating hormone levels should be considered.

According to a literature search, none of the previously performed Van cat studies related alterations in hormone and biochemical levels to tail gland hyperplasia. With this study, alterations in some hormone and biochemical levels were therefore studied in Turkish Van cats for the first time. In this study, despite not being statistically significant testosterone levels were higher in the study group $(452.42 \pm 68.84 \mathrm{ng} / \mathrm{dL})$ than in the control group $(315.83 \pm 76.39 \mathrm{ng} / \mathrm{dL})$. We believe this serum testosterone level increase in cats with tail gland hyperplasia is specifically associated with the tail gland hyperplasia, and this is similar to the findings of previous studies $(4,5,8,10)$.

Biochemical parameters such as ALP $(\mathrm{p}<0.01)$, AST $(\mathrm{p}<0.05)$, cholesterol $(\mathrm{p}<0.05)$ and triglyceride levels $(\mathrm{p}<0.05)$ were statistically significant between the groups. Differences between other biochemical parameters were not statistically significant. It was observed that AST and cholesterol levels were higher in the study group than in control group, whilst ALP and triglyceride levels were lower. However, these parameters (ALP, AST, cholesterol, and triglyceride) were determined to be within the range of reference values reported previously for cats $(7,9)$, and that these differences were not significant and resulted from individual variation. Despite their limited study, Ural et al. (2008) did not determine any alterations in the hematological and biochemical parameters of cats with tail gland hyperplasia. Similarly, in the present study no significant or specific alterations were detected in Turkish Van cats with tail gland hyperplasia.

In places where multiple cats are housed, determining the main cause of the disease and taking protective measures is more important in order to prevent the disease. Furthermore, in animals with white hair like Turkish Van cats, lesions on the tail are more severe and the appearance draws attention. The Yuzuncu Yil University Van Cat Research and Practice Center is a continuously visited place, and the animals are always in view, so visitor complaints were accepted as an important problem relating to this subject.

In conclusion, tail gland hyperplasia is also important in Turkish Van cats. It often occurs in adult males during and after mating season, and disease development may be related to the increase in testosterone levels at these times. As there are limited reports related to this disease in cats, presenting hormone and biochemical parameters for the first time is considered to be useful. It is also concluded that this study will be useful for researchers and clinicians. It will lead to further future studies as more detailed research should be performed in order to reveal the cause and hormonal aspects of the disease.

\section{References}

1. Albanese F.: Morphology and function of skin cells, [in:] Canine and Feline Skin Cytology. Springer, USA 2017, p. 1-39.

2.Axnér E., Ström B., Linde-Forsberg C., Gustavsson I., Lindblad K., Wallgren M.: Reproductive disorders in 10 domestic male cats. J. Small Anim. Pract. 1996, 37, 394-401

3. Briggs O. M.: Practical small animal dermatology. I: Structure and function of the skin. J. S. Afr. Vet. Assoc. 1987, 58, 229-231.

4. Dicle O.: Endokrin hastalıklarda gözlenen deri bulguları. Klinik Gelişim. 2009, 22, 46-51.

5. Gökalp H., Aksakal A. B.: Comparison of the efficacy of isotretinoin, cyproterone acetate/ethynil estradiol and combination therapies on serum androgenic hormone levels in females with acne vulgaris. Turkderm 2012, 46, 206-209.

6. Hnilica K. A., Patterson A. P.: Small Animal Dermatology. A Color Atlas and Therapeutic Guide. $4^{\text {th }}$ Ed. Elsevier 2017, p. 401-402.

7. Kahn C. M.: The Merck Veterinary Manual. $10^{\text {th }}$ ed Courier Kendallville Inc. Indiana, USA 2010, p. 2826

8. Kalinbacak A., Guzel M., Atalay O.: Stud tail in an Ankara cat. J. Turk Vet. Surg. 2002, 8, 91.

9. Kaneko J. J., Harvey J. W., Bruss M. L.: Clinical Biochemistry of Domestic Animals. Academic Press, California, USA 1997, p. 895-902.

10. Kapulu N., Turel Ermertcan A., Sahin M. T., Inanır I., Ozturkcan S.: Postadolescent acne in the spectrum of acne. J. Adnan Menderes Univ. Med. Fac. 2003, 4, 5-8

11. Kayar A., Ozkan C., Iskefli O., Kaya A., Kozat S., Akgul Y., Gonul R., Or M. E.: Measurement of M-mode echocardiographic parameters in healthy adult Van cats. Jpn. J. Vet. Res. 2014, 62, 5-15.

12. Nuttall T., Harvey R. G., Mckeever P. J.: A Colour Handbook of Skin Diseases of the Dog and Cat. Manson Publishing, UK 2009, p. 244-245.

13. Ozkan C., Kozat S., Kaya A., Akgul Y.: Some hematological and biochemical parameter levels in healthy Van cats at different age and gender. Eurasian J. Vet. Sci. 2016, 32, 214-219.

14. Paterson S.: Manual of Skin Diseases of the Dog and Cat. Blackwell Publishing 2008, $2^{\text {nd }}$ Ed., Chapter 17, p. 281-282.

15. Ruth J.: Poor haircoat in a Persian. Feline tail gland hyperplasia (FTGH). Compend. Contin. Educ. Vet. 2009, 31, 208-210.

16. Scott D., Miller W., Griffin C.: Muller and Kirk's Small Animal Dermatology. $6^{\text {th }}$ Ed. 2001, p. 1046-1048.

17. Shabadash S. A., Zelikina T. I.: The tail gland of canids. Biology Bulletin 2004, 31, 367-376

18. Turgut K., Borku M. K.: Kedi ve Kopek Dermatolojisi. Bahcivanlar Basim Sanayi A.S., Konya, Turkey 2002, p. 263-264.

19. Ural K., Acar A., Guzel M., Karakurum M. C., Cenker C. C.: Topical retinoic acid in the treatment of feline tail gland hyperplasia (Stud Tail): A prospective clinical trial. B. Vet. I. Pulawy 2008, 52, 457-459.

20. Yuksek N., Kaya A., Altug N., Ozkan C., Agaoglu Z. T.: Prevalence of feline retrovirus infections in Van Cats. B. Vet. I. Pulawy 2005, 49, 375-377.

Corresponding author: Abdullah KAYAR, DVM, PhD, Istanbul University-Cerrahpasa, 34320, Avcilar, Istanbul-Turkey; e-mail: kayar@ istanbul.edu.tr 